\title{
Research on the Collaborative Education of Ideological and Political Education under the Guidance of Party Construction
}

\author{
Zhonghui Xue, Jie Lai, Qianfeng Ma \\ Shanghai Publishing and Printing College, Shanghai, China \\ Email: hnlgxzh@163.com
}

How to cite this paper: Xue, Z.H., Lai, J. and Ma, Q.F. (2021) Research on the Collaborative Education of Ideological and Political Education under the Guidance of Party Construction. Open Access Library Journal, 8: e7259

https://doi.org/10.4236/oalib.1107259

Received: February 22, 2021

Accepted: May 25, 2021

Published: May 28, 2021

Copyright () 2021 by author(s) and Open Access Library Inc.

This work is licensed under the Creative

Commons Attribution International

License (CC BY 4.0).

http://creativecommons.org/licenses/by/4.0/

\begin{abstract}
The Party building is a great project. As the educational idea of the Party Central Committee in the new era, the ideological and political curriculum must hold high the banner of Party construction. At present, from the perspective of Party building to explore the new era of socialist builders and successors of moral education is a need to continue to strengthen the topic. Starting from the possibility, necessity and sufficiency of the combination of Party building and ideological and political education in Colleges and universities, this paper explores how teachers carry out the ideological and political education reform in classroom teaching and competition activities under the banner of Party building, so as to establish a new practice of Party building leading the ideological and political education reform.
\end{abstract}

\section{Subject Areas}

Curriculum Development, Educational Reform

\section{Keywords}

Party Building, Moral Education,

Curriculum Ideological and Political Education

\section{1. 前言}

全面推进高校课程思政建设是深入贯彻落实习近平总书记关于教育的重 要论述和全国教育大会精神的重要举措, 也是落实立德树人根本任务的战略 举措。教学活动的主体是学生和老师, 其中, 教师是关键, 思政是重点也是 难点。习近平总书记指出传道者首先要明道信道, 讲信仰的人首先要有信仰。 目前，教师思政意识培养及其对思政元素的深入挖掘过程中仍面临一些困惑， 
直接影响着思政课程和课程思政育人的效果。课程思政教学改革和党建工作 是高校的主体工作, 如何把两个主体工作融为一体是一个需要不断思考和不 断深化的课题。

党的建设建是一个伟大工程, 高校的课程思政是一项系统工程, 高校应 始终坚持以习近平新时代中国特色社会主义思想为指导, 以高质量高校教师 党建工作破解 “课程思政” 之惑, 为 “课程思政指路” , 不断丰富课程思政 的内涵, 不断探索课程思政建设的方法路径, 切实落实好立德树人的根本任 务。李莎莉等从高校党建和立德树人的新理念课程思政的主体性、内容性和 目标性出发探究党建如何破解 “课程思政” 中的 “思政”之惑 [1]。姜立新认 为充分发挥各级党组织的引领作用, 强化顶层设计、全面规划, 逐步推进课 程思政的体系化建设是关键 [2]。孟津竹等梳理了 “党建+课程思政” 体系下 育人工作发展的时代背景及内涵, 对当前高校育人工作进行 SWOT 分析[3]。 李鹏指出构建党的建设一一教学管理一一课堂教学的共建共享、互通互融的 平台, 将基层党组织党建工作与教学管理过程、教学系(教研室)教研活动相 互融合、相互促进，将思政元素融入教育教学全过程，才能实现真正的 “课 程思政” [4]。高校中的党员教师要成为马克思主义的坚定信仰者, 党的教育 方针的忠实执行者, 就必须把加强自身的党性修养放在重要位置, 因为教师 的信仰是会渗透于学生对人生观、价值观和世界观的持有, 构成学生之思想 灵魂, 事关学生之成长成才。而且给 “拔节孕穗期” 的莘莘学子传播知识、 传播真理, 其首要目的就是教育和引导学生发现科学信仰、选择科学信仰、 确立科学信仰、坚守科学信仰和践履科学信仰 [5]。

从文献资料调研的数量来看, 开展党建引领或者党建结合课程思政研究 的论文数量较少, 研究深度和广度够不够。比如教师和学生的主体地位如何 在党建和课程思政改革中进行融合, 党建和课程思政的学理联系是什么? 党 建在哪些方面可以有效的提升课程思政的效率和质量。这些问题都必须从党 建的本质和课程思政本质、党建的目标任务和课程思政的目标任务, 党建的 内容和课程思政的内容等方面进行探究, 为培养德智体美劳全面发展的社会 主义建设者和接班人形成同向的合力。

本文从党建和课程思政融合的必要性、充分性和可能性的角度分别进行 了探究。

\section{2. 党建和课程思政融合的必要性}

党的建设要求高校做作为立德树人的主要阵地, 承担着为实现民族复兴 的中国梦培育合格建设者和可靠接班人的重要任务。从党的建设在高校的具 体要求来看, 要把党治国理政的理念、规划蓝图、方针政策、思想方法和意 思形态提现到具体的育人活动中去, 比如党的政治建设、组织建设等方面, 必须结合具体的教学教育实践活动进行, 提高学生的政治向心力和思想亲和 力; 从课程思政的内涵来看, 课程思政 “思” 的就是如何通过把党的信仰和 国家梦想, 民族期望和人民重托, 如何聚集形式的落实到三位一体(价值塑造, 能力培养, 知识传授)的具体实践中。综合来说就是 “课” 中的 “思” 要落脚 
在党建的宽阔而又具体的伟大工程中去, 而且要做到 “程” 中 “政” , 即通 过体系化、系统化、科学化和程式化的课程体系把党建引领作用旗帜鲜明的 “引出来”、“领出来”。

纵观历史脉络, 一个政党的建设, 特别是在高校的党建, 都是通过教育 和教学的具体实践中得到实践、建设和强化的。习近平总书记在北京大学师 生座谈会上的讲话中指出, “古今中外, 每个国家都是按照自己的政治要求 来培养人的, 世界一流大学都是在服务自己国家发展中成长起来的。我国社 会主义教育就是要培养社会主义建设者和接班人”, 总书记的讲话清楚地为 我们育人指明了方向, 就是要按照中华民族伟大复兴的中国梦要求来为党育 人, 为国育才。课程建设的重要理念 “课程思政” , 只有以党的建设的指引 为指引, 以党的建设的具体要求为要求来落实立德树人的目标, 才能形成行 之有效的系统育人工程。没有党建引领的课程思政不是真正有效的课程思政, 至少是不能够走的长远的课程思政。而没有课程思政相融合的高校党建也是 缺少具体实践载体的党建, 会让党的建设空洞化和口号化。全面推进课程思 政建设这一战略举措, 影响甚至决定着接班人问题, 影响甚至决定着国家长 治久安, 影响甚至决定着民族复兴和国家崛起。高校教师党建和课程思政建 设都肩负着不可回避的历史使命, 那就是努力培养担当民族复兴大任的时代 新人, 培养德智体美劳全面发展的社会主义建设者和接班人。厘清这个本意, 在思政元素的挖掘和渗透中, 就容易有效防止 “贴标签” “两张皮” , 避免 形式主义和教条主义; 在教学设计中, 更利于增强主动性, 深化理念和想法, 避免被动应付、生搬硬套。高质量教师党建有助于课程思政建设提高政治站 位, 强化责任担当, 提升思政育人能力。

\section{3. 党建引领课程思政立德树人的充分性}

党的建设为了人民, 为了中华民族的伟大复兴, 为了国家永久的繁荣昌 盛, 为了实现人民为中心的永久执政。具体来讲就是习总书记多次强调的“人 民至上” 和 “人民为中心”。而课程思政是新时代高校落实立德树人、以人 民为中心进行课程改革的具体举措, 就是要把思想政治教育和知识教育融通 起来, 把信念理想渗透和科学思维结合起来。高校作为学术和教育重地, 承 担着培养时代新人的重任。时代新人的内涵必须要拥护党的领导, 坚定不移 的拥护党的领导及其党领导下进行社会主义的具体实践。党的十九大的报告 指出, 党领导一切, 具体到高校, 就是要以育人育才工作为中心, 在党的领 导下, 落实党建的教育教学基因, 发挥党建在高校工作的引领作用。因此高 校应该也必须破解党建在学术、教学、教育中的实践的壁垒和藩篱, 旗帜鲜 明的高举党建的旗帜, 把党建引领的旗帜插到每一个专业、每一门课程和每 一次的教学实践中去。方向决定道路, 道路决定方法, 方法决定选择的途径。 党的建设给课程思政建设明确 “为党育人, 为国育才” 的方向、提供 “同向 同行协同育人” 的道路指引和方法路径。所以课程思政建设必须要以党的建 设为旗帜鲜明的引领, 引导教育者和受教育者, 在教书育人和学习中信仰真 理、传播真理。总而言之, 高校的党建的要求为课程思政提供了充分的遵循。 


\section{4. 党建引领课程思政建设的可行性分析}

从事课程思政的主体是高校的教职员工, 课程思政的狭义受众是处于求 职旺盛期的青年学子。教师作为党的教育工作者承担的不仅是传播知识, 更 要传播真理、宣扬党的方针和政策等。学生作为课程思政的受众, 不仅仅是 学生, 更是未来的建设者和接班人, 没有合格的灵魂, 没有高尚的情操, 没 有过硬的抵御风险的信仰, 不可能在漫长的实践中永葆本色, 初心不改。而 课程中的知识除了工具价值属性, 更具有理性价值属性和育人价值基因, 发 挥价值基因塑造人的灵魂和修养的作用本身就是党建的应有之义。党的建设 狭义上好像仅仅是对党员要做的一项教育工作, 但每一个教育工作者都是在 党的领导下从事的教育工作。“东西南北中, 党是领导一切的。” 这就要求 非党员教师也要主动的在党建工作的指引下开展教育教学工作, 把立德树人 的载体课程思政作好作强。而党员教师更加应该把党建的知识、内容、思想 和精神运用到具体的教育教学实践中去, 作先锋模范的带头作用。一个高校 的育人育才工作是一盘棋, 党建是指挥。没有高效的有质量的党建作指引, 课程思政就会办成无源之水无本之木, 不能够形成科学性和系统性, 就会迷 失方向。党建的内容和课程思政的 “思” , 不论在目标上、内容上, 还是在 本质上和主体上都是一致的, 统一的 [1]。这些统一为党建引领课程思政提供 了可行性和融通性。在具体的实践中, 要激励广大党员干部教师怀着一颗党 性党心, 立足本职岗位和正在做的事, 干事创业、建功立业, 在教书育人的 具体工作中浸润家国情怀、担当社会责任、体现科学精神, 发挥和体现党组 织的战斗堡垒、党员先锋模范作用。学校可以通过设立党员先锋岗、划定党 员责任区、改革党建工作评价办法和指标体系等一系列具体举措, 推动党员 将先锋模范作用发挥与业务工作实绩有机结合, 将党建政治软实力转化为学 校发展硬实力。党建和课程思政融合的可行性分析如表 1 所示。

\section{5. 党建引领课程思政的具体实践}

\section{1. 党建引领下数学教研室课程思政建设全覆盖}

数学教研室大类课程《微积分》类和《工程数学》类两门, 另外还承担 有《数文明》、《数学素质拓展》和《高等数学》校公选课, 这些内容都落 实了立德树人的要求, 分别在党建引领下实现了课程思政的全面化、体系化 和系统化(表 2)。

\section{2. 党建引领下承担的全国数学建模竞赛的具体实践}

在疫情防控常态化背景下, 发挥学生入党积极分子的带头作用, 组建参 赛小组。在积极分子的带头作用下, 为了能及时赶到学校, 递交多份返校申 请。很多同学为了配合返校时间多次更改航班, 只为了能准时到达学校、顺 利参赛。最终在学校、党员指导老师和同学们的不解努力之下, 开展了为期 四天的赛前培训。比赛题目难度比校内选拔题目难度要高, 同学们不止在和 高难度的题目做较量, 同时也在和自己的身体、心态和信仰理念做较量。可 以说所有的参赛选手为了这次比赛恨不得 “头悬梁, 雉刺股” , 心理上的焦 
表 1. 党建和课程思政融合的可行性分析表

\begin{tabular}{|c|c|c|c|c|}
\hline $\begin{array}{l}\text { 项目 } \\
\text { 内容 }\end{array}$ & 内容和框架 & $\begin{array}{l}\text { 主体 } \\
\text { 和对 } \\
\text { 象 }\end{array}$ & 形式和途径 & 目标 \\
\hline $\begin{array}{l}\text { 党的 } \\
\text { 建设 }\end{array}$ & $\begin{array}{l}\text { 思想建设、组织建设、作风建 } \\
\text { 设、反腐倡廉建设、制度建设。 } \\
\text { 习近平总书记系列重要讲话 } \\
\text { 精神和治国理政新理念新思 } \\
\text { 想新战略学习教育; 马克思列 } \\
\text { 宁主义、毛泽东思想教育和中 } \\
\text { 国特色社会主义理论体系的 } \\
\text { 教育, 党的基本路线、基本纲 } \\
\text { 领和基本知识教育; 坚持正确 } \\
\text { 的政治方向、政治立场、政治 } \\
\text { 原则等是重要内容等 }\end{array}$ & $\begin{array}{l}\text { 党员 } \\
\text { 师生 } \\
\text { 党员 } \\
\text { 教师 } \\
\text { 模范 } \\
\text { 带动 } \\
\text { 下的 } \\
\text { 全体 } \\
\text { 教师 }\end{array}$ & $\begin{array}{l}\text { 党课, 支部活 } \\
\text { 动; 专题讨论 } \\
\text { 课。结合教育 } \\
\text { 教学工作学四 } \\
\text { 史; 体系式学 } \\
\text { 习、融合式讨 } \\
\text { 论、案例式教 } \\
\text { 学、项目式研 } \\
\text { 究, 显性和隐 } \\
\text { 性相结合 }\end{array}$ & $\begin{array}{l}\text { 一是把党建设得更加 } \\
\text { 坚强有力; 二是不断 } \\
\text { 提高党的建设质量; } \\
\text { 三是把党建设成为始 } \\
\text { 终走在时代前列、人 } \\
\text { 民衷心拥护、勇于自 } \\
\text { 我革命、经得起各种 } \\
\text { 风浪考验、朝气蓬勃 } \\
\text { 的马葸主义执政 } \\
\text { 党。 }\end{array}$ \\
\hline $\begin{array}{l}\text { 课程 } \\
\text { 思政 }\end{array}$ & $\begin{array}{l}\text { 爱党、爱国、爱社会主义、爱 } \\
\text { 人民、爱集体为主线, 系统进 } \\
\text { 行中国特色社会主义和中国 } \\
\text { 梦教育、社会主义核心价值观 } \\
\text { 教育、法制教育、劳动教育、 } \\
\text { 心理健康教育、美学教育、艰 } \\
\text { 苦奋斗教育、中华优秀传统文 } \\
\text { 化教育 }\end{array}$ & $\begin{array}{l}\text { 全体 } \\
\text { 教师 } \\
\text { 全体 } \\
\text { 学生 }\end{array}$ & $\begin{array}{l}\text { 课堂是主渠 } \\
\text { 道, 各种有利 } \\
\text { 于促进学生思 } \\
\text { 想价值提升的 } \\
\text { 有效途径。显 } \\
\text { 性和隐性相 } \\
\text { 结合 }\end{array}$ & $\begin{array}{l}\text { 通过课程思政的教学 } \\
\text { 改革, 培养合格的建 } \\
\text { 设者和加班人。时代 } \\
\text { 新人。 }\end{array}$ \\
\hline 可行性 & 内容高度一致 & $\begin{array}{l}\text { 主体 } \\
\text { 相同 }\end{array}$ & 途径相通 & 目标融合贯通 \\
\hline
\end{tabular}

表 2. 党建引领下教研室的课程思政实践

\begin{tabular}{|c|c|c|c|c|c|}
\hline $\begin{array}{l}\text { 序 } \\
\text { 号 }\end{array}$ & & 内容 & 形式 & 负责人 & 参加人员 \\
\hline 1 & & $\begin{array}{l}\text { 1) 习近平总书记关于教育的重 } \\
\text { 要论述 }\end{array}$ & 讲座 & 薛中会 & $\begin{array}{l}\text { 教研室全体 } \\
\text { 教师 }\end{array}$ \\
\hline 2 & & $\begin{array}{l}\text { 2) 习近平总书记在全国教育大 } \\
\text { 会上的重要讲话 }\end{array}$ & 讲座 & 薛中会 & $\begin{array}{l}\text { 教研室全体 } \\
\text { 教师 }\end{array}$ \\
\hline 3 & $\begin{array}{l}\text { 理论学 } \\
\text { 习篇 }\end{array}$ & $\begin{array}{l}\text { 3) 《高等学校课程思政建设指导 } \\
\text { 纲要》 }\end{array}$ & 讲座 & 薛中会 & $\begin{array}{l}\text { 教研室全体 } \\
\text { 教师 }\end{array}$ \\
\hline 4 & & $\begin{array}{l}\text { 4) “践行新时代教育使命、深挖 } \\
\text { 课程思政元素、精耕思政沃土” } \\
\text { 专题培训 }\end{array}$ & 讲座 & 薛中会 & $\begin{array}{l}\text { 教研室全体 } \\
\text { 教师 }\end{array}$ \\
\hline 5 & & $\begin{array}{l}\text { 1) 《微积分》课程思政教学设计 } \\
\text { 研讨 }\end{array}$ & 研讨 & 薛中会 & $\begin{array}{l}\text { 教研室全体 } \\
\text { 教师 }\end{array}$ \\
\hline 6 & 行动实 & $\begin{array}{l}\text { 2) 课程思政示范课堂观摩与学 } \\
\text { 习 }\end{array}$ & $\begin{array}{l}\text { 公开课观摩 } \\
\text { 学习 }\end{array}$ & 薛中会 & $\begin{array}{l}\text { 教研室全体 } \\
\text { 教师 }\end{array}$ \\
\hline 7 & 践篇 & $\begin{array}{l}\text { 3) 《工程数学》课程思政优秀案 } \\
\text { 例遴选 }\end{array}$ & 案例示范 & 薛中会 & $\begin{array}{l}\text { 教研室全体 } \\
\text { 教师 }\end{array}$ \\
\hline 8 & & $\begin{array}{l}\text { 4) 教研室课程思政负责人说思 } \\
\text { 政的 “思” 和 “政” }\end{array}$ & 专业思政 & 方恩印 & $\begin{array}{l}\text { 教研室全体 } \\
\text { 教师 }\end{array}$ \\
\hline 9 & $\begin{array}{l}\text { 总结交 } \\
\text { 流篇 }\end{array}$ & $\begin{array}{l}\text { 1) 课程思政实施成效阶段性展 } \\
\text { 示、反馈与总结 }\end{array}$ & $\begin{array}{l}\text { 展示、交流 } \\
\text { 总结 }\end{array}$ & 薛中会 & $\begin{array}{l}\text { 教研室全体 } \\
\text { 教师 }\end{array}$ \\
\hline
\end{tabular}


虑非常容易让同学们陷入自我怀疑的漩浴中。指导老师的指导再加上同学们 的顽强拼搏, 不止克服了这些困难, 还在比赛中取得了优秀的成绩。总结疫 情下的参赛经历, 指导教师和参赛同学感慨良多, 但感受最深的是正确的世 界观和方法论的指引, 心中要有信仰和梦想。正如习近平总书记所讲 “心中 有信仰, 脚下有力量” 。参赛同学对教练组说 “没有老师在课堂上对知识思 想价值、应用价值的融汇贯通的讲解, 提升不了他们看待事物的眼界和格局、 解决问题的能力也无从谈起”。由此党的建设在高校要落地坐实必须与具体 的实践, 尤其是课程思政的课堂建设相结合。

\section{3. 党建引领下在线课程的思政化教学改革}

2020 年疫情期间, 在工程数学在线开放课程授课和平台上, 有党员老师 牵头, 任课老师以党建为引领, 坚持课程在哪里党建就在哪里, 收集和开发 各种资源, 打好疫情下的线上授课工作, 保质保量的完成学校任务。没有好 的课程建设, 思政育人便显得虚无缥纱、华而不实, 也难以让学生接受、信 服。没有党建的引领, 为谁培养人的问题就会会迷失方向。因此要把党建的 内容、要求、内涵等以潜移默化的形式渗透于线上课程中去, 不让线上成为 党建课程思政的空地。

\section{4. 在党建引领下, 课堂上发挥入党积极分子的作用, 促进知识教育、 思想教育和政治教育的有效融合}

在党员教师的指引下, 学生组建学习小组, 以入党积极分子为组长, 发 挥积极分子的模范到头作用, 遵守课堂纪律, 尊敬老师, 发挥互助互帮的优 良传统, 不断提高学习的积极性和主动性, 把爱国落实到学子的实践中, 教 师把育人落实到教学的整个过程中。作为一线的教师, 融合与学生成长过程 是幸福的也是快乐的。能够在和学生的敞开心扉的交流过程中, 摸准学生思 想上的疑难点, 知识上的堵点, 精神上的疑虑。引导积极分子, 开展课堂知 识和思想的交流, 解疑难, 疏通堵点, 破解疑虑。

\section{6. 总结}

以上分析可以看出二者党建和课程思政具有内在密切联系性和广泛的契 合性, 是辩证统一的关系。站在历史和未来的角度, 从学生的需要出发, 从 党的建设的重要性加压, 每一个教育工作者都会深深的感受到在课程建设中, 在课程思政的具体措施中, 树立党建引领的必要性和重要性。课程思政中的

“思政” 味道是马克思主义信仰味道, 这种信仰的味道能够给人以攴智和坚 毅、高尚和文明, 使之成为脱离了低级趣味的人、顶天立地的人。课程思政 就是让有信仰的人将信仰的具体实践, 没有深入透彻的具体的实践, 党的建 设会成为一句标题和口号, 而高效党建又必须以课程思政的改革实践为重要的 阵地和抓手, 提高党建的内涵的同时, 有效地提升的课程思政的高度和深度。

\section{致谢}

本文受上海出版印刷高等专科学校 2020 创新创业课题 “创新创业背景下 
高职高专数学课教学改革研究” 资助。

\section{Conflicts of Interest}

The authors declare no conflicts of interest regarding the publication of this paper.

\section{References}

[1] 李莎莉, 吕丽. 以高质量高校教师党建工作破解“课程思政”之惑 [EB/OL]. 半月 谈网, 2020-09-23.

http://www.banyuetan.org/ppsj/detail/20200923/10002000331382816008749759174 84678_1.html

[2] 逢卉一. 党建统领 协同推进 扎实做好课程思政建设 [J]. 山东教育 (高教), 2020(11): 28-29.

[3] 孟津竹, 陈四利, 韩永强, 等. “党建+课程思政”体系下高校专业课教师育人队伍 的构建 [J]. 高教学刊, 2020(10): 125-128.

[4] 李鹏. “党建引领 道术并举”一一地方应用型高校课程思政实践路径研究 [J]. 辽 东学院学报(社会科学版), 2020(5): 116-120.

[5] 张智. 让有信仰的人讲信仰 [EB/OL]. 中国共产党新闻网, 2019-03-29.http://theory.people.com.cn/n1/2019/0329/c40531-31002105.html

\section{Appendix (Abstract and Keywords in Chinese)}

\section{党建引领下的课程思政协同育人}

摘要: 党的建设是一个伟大的工程, 课程思政作为党中央在新时代的教 育理念, 必须高举党建旗帜。目前, 从党建的视角探究新时代社会主义建设 者和接班人的立德树人是一个需要不断加强的课题。本文从高校党建和课程 思政相结合的可能性、必要性和充分性出发, 探究教师如何在以党建为旗帜, 在课堂教学和竞赛活动中开展课程思政教学改革, 为建立一套党建引领课程 思政立德树人教学改革的新实践进行努力探索。

关键词: 党建, 立德树人, 课程思政 